\title{
Peribulbar Versus Retrobulbar Anaesthesia
}

\author{
I. E. MURDOCH \\ London
}

\begin{abstract}
Summary
A prospective clinical trial comparing peribulbar with retrobulbar anaesthesia is reported. Ninety-nine consecutive patients for cataract extraction under local anaesthesia were randomly allocated to a peribulbar or retrobulbar technique. The effectiveness of the anaesthetic, the operative conditions, and the degree of patient discomfort were recorded.

Pain scores (as assessed separately by the patient, surgeon, and attendant nurse) demonstrated that anaesthetic administration and surgery were less painful with the peribulbar method. This technique gave more reliable ocular akinesia and orbicularis oculi paralysis in addition to a lower operative complication rate.
\end{abstract}

Local anaesthesia in place of general anaesthesia for cataract surgery is becoming more popular in the United Kingdom, especially with the advent of day-case surgery. Much attention has recently been focused on the potential dangers of local anaesthesia, in particular with the retrobulbar technique. ${ }^{1,2,3}$ One example of a local anaesthetic technique claiming to avoid these complications is the peribulbar technique first described by Davis and Mandel. ${ }^{4}$

This is a report of a prospective trial comparing the retrobulbar technique with the peribulbar technique from both the surgeons' point of view and that of the patients.

\section{Method}

Patients admitted sequentially to the Sutton Eye Unit for cataract extraction and listed for surgery under local anaesthetic were randomised to receive either the retrobulbar technique or the peribulbar technique. The trial was explained and all consented to take part in the trial. Randomisation was achieved by means of a random number assigned to each patient, those with even numbers received peribulbar anaesthesia and those with odd numbers received retrobulbar anaesthesia.

A standard premedication of $\mathrm{G}$. phenylephrine $10 \%$, G. cyclopentolate $1 \%$ and G. proxymetacaine $0.5 \%$ was given topically at $60,45,30$ and 15 minutes prior to operation.

Four surgeons performed the operations. Three gave no additional premedication and one surgeon gave $10 \mathrm{mg}$ Temazepam orally two hours before surgery. The patients were equally distributed between surgeons.

In theatre the surgeon ascertained which technique was to be used and administered the anaesthetic according to a standard protocol.

\section{Injection techniques}

With both techniques the injection sites were cleaned with a chlorhexidine and cetrimide soaked swab (Medi-swab).

The retrobulbar technique uses $5 \mathrm{mls}$ of a $50 / 50 \mathrm{mix}$ of $2 \%$ lignocaine and $0.5 \%$ bupivicaine. A non-disposable retrobulbar needle is introduced through the skin one centimetre below the lid margin at the junction of the middle and lateral thirds. It is then directed 
superiorly and medially to enter the muscle cone. One millilitre of local anaesthetic solution is injected at the posterior part of the muscle cone. A small amount of anaesthetic is then injected subconjunctivally at the insertion of the superior rectus muscle before a facial block is given according to the method of O'Brien. The eye is then massaged for five minutes manually.

The term retrobulbar technique will be used to signify this whole procedure and the terms retrobulbar block and O'Brien facial block used for the individual components.

The peribulbar technique uses two anaesthetic mixes. The first is one millilitre of $2 \%$ lignocaine in $9 \mathrm{mls}$ of $0.9 \%$ sodium chloride for the superficial injection. The second is $6 \mathrm{mls}$ of a $50 / 50$ mixture of bupivicaine $0.5 \%$ and lignocaine $2 \%$ with 1,500 IU of hyaluronidase. The diluted lignocaine is administered through a short 27 gauge needle and the 50/50 mix through a non-disposable retrobulbar needle.

The two sites of injection are at the junction of the middle and lateral thirds of the lower lid and the supraorbital notch. The first two injections are dilute lignocaine. The needle is entered to the hilt at the orbital rim, and $1 \frac{1}{2}-2 \mathrm{mls}$ of anaesthetic solution injected at each site. This is designed to render the deep peribulbar injection less painful. Using the $50 / 50 \mathrm{mix}$, the needle is introduced perpendicular to the skin and one centimetre deep. One $\mathrm{ml}$ of solution is injected. The needle is advanced to $2 \mathrm{~cm}$ depth and a further one millilitre injected. Inclining the needle slightly upwards and medially, it is advanced to $3 \mathrm{~cm}$ depth for the final one millilitre. This is repeated superiorly but remains perpendicular throughout. The inferior peribulbar injection must always be given first and, while learning the technique, the globe may be gently displaced inferolaterally away from the superior needle. Manual ocular message is then given for five minutes.

Four questionnaire forms were designed for completion on each patient. The first was completed by the ward nurse, the second by the attendant theatre nurse, the third after questioning the patient, and the final one by the surgeon. As most of the measurements being made were subjective assessments by the patient or medical attendant, they were scored on a $1-10$ scale.

Examples are given below:

Degree of anxiety on way to theatre (ward nurse)

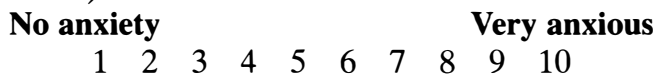

Degree of discomfort caused by injections (patient)

No pain

$$
\begin{array}{llllllllll}
1 & 2 & 3 & 4 & 5 & 6 & 7 & 8 & 9 & 10
\end{array}
$$

\section{Ward questionnaire}

The ward nurses were asked to assess patient anxiety independently over the 24 hour period before surgery and immediately preoperatively. In addition they scored their impression of the discomfort caused by the pre-operative drops and patient discomfort on return from theatre. Space was given for comments by nurse and patient and any drugs requested over the first 24 hours post-operatively were recorded.

\section{Theatre nurse questionnaire}

The theatre nurse holding the patient's hand throughout the anaesthetic administration and the operation independently assessed the anxiety of the patient, and the apparent degree of discomfort of anaesthetic administration and of the operation. Comments were invited at all stages.

\section{Patient questionnaire}

The patient was asked by the surgeon in the anaesthetic room to assess the degree of discomfort caused by the drops in the premedication. Peribulbar or retrobulbar anaesthetic was then administered and immediately afterwards the patient was asked to assess the degree of discomfort caused. Patients were also asked if any one of the injections was particularly painful. Immediately after the operation the patient was asked to assess separately the degree of discomfort of the operation and of the final subconjunctival antibiotic. The day after the operation the patients were again asked to assess the level of discomfort of the whole procedure. Comments were invited throughout. 


\section{Surgeons questionnaire}

The surgeon assessed independently the degree of discomfort caused by the anaesthetic administration, the operation, and the subconjunctival antibiotic. The effectiveness of orbicularis oculi paralysis was assessed by the extent of lash burial on attempted eyelid closure. Five grades were used, good, moderate and mild lash burial, closure but no lash burial and complete paralysis. The degree of ocular akinesia was assessed by measuring with a caliper the movements of the limbus from straight-ahead gaze medially, laterally, superiorly and inferiorly.

The operations were all planned extracapsular extractions, the vast majority with posterior chamber intraocular lens implantation. Each stage of the operation was scored for ease of achievement on a scale of 1-10 and any complications recorded. Comments were invited.

\section{Results}

Ninety-nine patients were included in the trial. Fifty-one received retrobulbar anaesthesia and 48 peribulbar. The sex and age distribution are shown in Table I.

The pre-operative anxiety scores showed a skew distribution towards the low nonanxious scores. There was little difference between the two groups in the two ward assessments [mean scores-peribulbar 2.9 [SD 2.6] and 2.5 [SD 2.2], retrobulbar 2.7 [SD 2.1] and 2.4 [SD 1.6]] however the peribulbar group were considered less anxious than the retrobulbar group by the theatre nurses on their arrival in the anaesthetic room [mean score-peribulbar 2.7 [SD 1.6] retrobulbar 4.2 [SD 2.4]]. If the pre-operative anxiety scores are pooled to a cumulative anxiety score then there is a symmetric distribution and no difference between the two groups [cumulat-

Table I

\begin{tabular}{lccccc}
\hline & \multicolumn{3}{c}{ Sex } & \\
\cline { 2 - 3 } & \multicolumn{2}{c}{$M$} & & $F$ & \\
\cline { 2 - 3 } & No. $\%$ & & No. $\%$ & $\begin{array}{c}\text { Mean age } \\
\text { (years) }\end{array}$ \\
\hline $\begin{array}{l}\text { Retrobulbar } \\
\text { Peribulbar }\end{array}$ & $14(27)$ & & $37(73)$ & 77.8 \\
Total & $19(40)$ & & 29 & $(60)$ & 79.5 \\
& $33(33)$ & & $66(67)$ & 78.3 \\
\hline
\end{tabular}

ive mean anxiety score retrobulbar 9.4 and peribulbar $8.4[\mathrm{p}=0.31$ - students t test $]]$.

\section{Assessment of pain}

The pain scores for the pre-operative drops showed that the peribulbar group considered the same drops more uncomfortable than the retrobulbar group. This was not considered to be the case by the ward nurses. The patient, the attendant nurse, and the surgeon all scored lower mean pain scores for the administration of anaesthetic by the peribulbar technique than by the retrobulbar technique. This trend was the same for operative discomfort scores and subconjunctival injection scores. The day after operation, however, there was virtually no difference between the pain scores in the two patient groups for the discomfort of the whole procedure. These results are tabulated in Table II. Additional topical anaesthesia was required by seven patients in each group. In response to the open ended question 'Did any one injection hurt more than the other?', the O'Brien facial block (23 $(45 \%)$ people) and retrobulbar block (18 (35\%) people) were the most frequently recorded by the retrobulbar group. For the peribulbar method the fourth (superior anaesthetic mix) injection (19 (40\%) people) was most often singled out. The answer of 'none' was given by $7(14 \%)$ people in the retrobulbar group and $16(33 \%)$ in the peribulbar group.

\section{Effectiveness of paralysis}

For the purposes of analysis the five points on the orbicularis oculi paralysis scale were divided into satisfactory paralysis (closure but no lash burial or complete paralysis) and unsatisfactory paralysis (mild, moderate or good lash burial) (Table III). The peribulbar method gave a more reliable orbicularis oculi paralysis in our hands (chi squared 5.21; p 0.05). Postoperatively a pad was required for persistent facial weakness in $18(38 \%)$ peribulbar cases and $20(39 \%)$ retrobulbar cases.

The measured ocular movements showed better paralysis in the peribulbar group in all directions of gaze except medially. This was especially evident with lateral gaze and upgaze (Table IV).

\section{Operative conditions}

Ease of capsulotomy, lens expression, aspir- 
Table II

\begin{tabular}{|c|c|c|c|c|}
\hline Time of observation & Observer & $\begin{array}{c}\text { Retrobulbar } \\
\text { m.p.s. }\end{array}$ & $\begin{array}{c}\text { Peribulbar } \\
\text { m.p.s. }\end{array}$ & $\begin{array}{c}\text { Unpaired } t \text { Test } \\
P=\end{array}$ \\
\hline Administration of & Patient & 2.9 & 3.6 & 0.08 \\
\hline pre-operative drops & Ward nurse & 1.7 & 1.9 & 0.49 \\
\hline Administration of & Patient & 5.8 & 4.8 & 0.04 \\
\hline \multirow[t]{2}{*}{ anaesthetic injection } & Nurse & 4.6 & 4.0 & 0.22 \\
\hline & Surgeon & 5.2 & 4.5 & 0.12 \\
\hline Sup. rectus fixation & Surgeon & 2.9 & 1.5 & 0.002 \\
\hline Discomfort during & Patient & 2.6 & 1.9 & 0.05 \\
\hline \multirow{2}{*}{ operation } & Nurse & 3.0 & 2.2 & 0.05 \\
\hline & Surgeon & 2.0 & 1.5 & 0.04 \\
\hline \multicolumn{5}{|l|}{ Administration of } \\
\hline subconjunctival & Patient & 3.7 & 3.0 & 0.18 \\
\hline antibiotic & Surgeon & 3.7 & 2.9 & 0.11 \\
\hline Day after operation & Patient & 3.6 & 3.5 & 0.91 \\
\hline
\end{tabular}

m.p.s. = mean pain score

ation of soft lens matter, and introduction of intraocular lens were all scored by the surgeon. There was no difference between the two groups except lens expression which was more easily achieved in the retrobulbar group. There was no difference between the groups in the recorded restlessness of patients during the operation.

Per-operative complications are shown for the two groups in Table $\mathrm{V}$.

The one retrobulbar haemorrhage necessitated cancellation of the operation. In the remaining cases the operation was completed with no immediate post-operative complications.

\section{Discussion}

The two populations in our trial were similar with regard to age and sex as a result of randomisation. Anxiety has been related to perception of pain, hence the inclusion of an anxiety score. This only showed a difference between the anxiety scores assessed by the theatre nurse in the anaesthetic room; the retrobulbar group seeming more anxious. This result was, however, overshadowed by the fact that the peribulbar group showed a lower pain threshold than the retrobulbar

Table III

\begin{tabular}{lcc}
\hline Paralysis & Retrobulbar & Peribulbar \\
\hline Unsatisfactory & 10 & 3 \\
Satisfactory & 41 & 45 \\
\hline
\end{tabular}

group as assessed by the pain scores for the preoperative drops. This suggests that if the pain thresholds had been similar in the two groups an even greater difference between the pain scores for the anaesthetic techniques would have been demonstrated.

The pain scores show that the technique of peribulbar anaesthesia used was considered less painful by patients when assessed immediately after administration. In addition, both patients and observers considered the per-operative anaesthesia better after peribulbar anaesthetic administration. Especially noteworthy was that surgeons considered the superior rectus fixation suture to be much less painful after the peribulbar technique despite having injected subconjunctival anaesthetic over the site as part of the retrobulbar technique.

Pain scores were consistently lower in the peribulbar group for anaesthetic administration. These differences were statistically significant for the patient but not for the sur-

Table IV

\begin{tabular}{lccc}
\hline & \multicolumn{3}{c}{$\begin{array}{c}\text { Mean movement of limbus } \\
(\mathrm{mm})\end{array}$} \\
\cline { 2 - 4 } $\begin{array}{l}\text { Direction of } \\
\text { gaze }\end{array}$ & $\begin{array}{c}\text { Retrobulbar } \\
(S D)\end{array}$ & $\begin{array}{c}\text { Peribulbar } \\
(S D)\end{array}$ & $\begin{array}{c}\text { Unpaired } \\
\text { t test } \\
P=\end{array}$ \\
\hline Lateral & $2.5(2.2)$ & $1.6(2.2)$ & 0.05 \\
Medial & $1.6(1.9)$ & $1.9(2.1)$ & 0.41 \\
Superior & $1.7(1.8)$ & $0.8(1.3)$ & 0.02 \\
Inferior & $1.3(1.6)$ & $1.0(1.6)$ & 0.47 \\
All directions & $1.8(1.4)$ & $1.3(1.5)$ & 0.13 \\
\hline
\end{tabular}


Table V

\begin{tabular}{lcc}
\hline Complication & Retrobulbar & Peribulbar \\
\hline $\begin{array}{l}\text { Retrobulbar haemorrhage } \\
\begin{array}{l}\text { Suspected } \\
\text { retrobulbar haemorrhage }\end{array}\end{array}$ & 1 & 0 \\
$\begin{array}{l}\text { Vitreous loss } \\
\begin{array}{l}\text { Posterior capsule tear } \\
\text { without vitreous loss }\end{array}\end{array}$ & 1 & 0 \\
$\begin{array}{l}\text { Bulging eye during } \\
\text { operation with iris } \\
\text { prolapse }\end{array}$ & 2 & 1 \\
\hline
\end{tabular}

geon and nurse assessments. With the sample size in this study one could expect to detect a difference in mean pain scores of 1.4 [variance $=2.01,5 \%$ significance] with a power of $90 \%$. Discomfort during the operation was significantly less in the peribulbar group. How important a pain difference of one unit is to the patient at the time of anaesthetic administration and surgery is a matter for individual consideration. Interestingly on the day after operation any difference noted by the two patient groups at the time of surgery had been completely forgotten and the pain scores of remembered discomfort were remarkably similar between the two groups.

The superior peribulbar injection was singled out as being the most painful with the peribulbar method. With increased practice of the technique it has been claimed that this injection may be omitted without sacrifice of anaesthetic effect. This may decrease the discomfort of this anaesthetic method still further. The peribulbar technique gave a paralysis of orbicularis oculi which was more reliable than the O'Brien facial block in our hands. Ocular mobility was also less with this technique. A notable point is that upgaze and, even more so, lateral gaze were least affected by retrobulbar block. This could have been the result of poor positioning of the retrobulbar block, but it is more likely that hyaluronidase affected more efficient distribution of the anaesthetic. ${ }^{5}$ If hyaluronidase were added to the retrobulbar anaesthetic mix, this difference might disappear.

With both retrobulbar and peribulbar tech- niques our results have only recorded the effects of a single attempt at anaesthetic block. In clinical practice inadequate anaesthesia or muscle paralysis may be supplemented by additional anaesthetic administration. In no case, however, was the anaesthetic so inadequate that surgery was not possible.

The primary aim of this study was to compare the peribulbar with the retrobulbar method of local anaesthesia for degree of discomfort of anaesthetic administration and effectiveness of anaesthetic block. We observed that the administration of the peribulbar method is no more painful than the retrobulbar method, and the per-operative discomfort is less with the peribulbar method. We also observed that it is more effective than the retrobulbar technique in our hands. In addition the study served to highlight a higher incidence of per-operative complications with the retrobulbar technique than with the peribulbar technique. This last point has been reported several times previously although not in a comparative trial. ${ }^{4,6,7}$

I would like to thank Mr. Roy Harfitt, Ms. Medea Frangoulis, Mr. Peter Fison and the medical and nursing staff at Sutton Hospital for their help and support. Mrs. M. Grice kindly undertook the secretarial work.

\section{References}

${ }^{1}$ Morgan OM, Schatz H, Vine AK, Cantrill L, Davidorf FH, Gitter KA, Rudich R. Ocular complications associated with retrobulbar injections. Ophthalmology 1988. 95: 660-5.

${ }^{2}$ Javitt JG, Addiego R, Friedberg HH, Libonati MM, Leahy JJ. Brain stem anaesthesia after retrobulbar block. Ophthalmology 1987, 94: 718-23.

${ }^{3}$ Wittpenn JR, Rapoza P, Sternberg P, Kuwashima L, Saklad J, Patz A. Respiratory arrest following retrobulbar anaesthesia. Ophthalmology 1986, 93, 867-70.

${ }^{4}$ Davis DB and Mandel MR. Posterior peribulbar anaesthesia: an alternative to retrobulbar anaesthesia. J Cataract Refract Surg 1986, 12, 182-4.

${ }^{5}$ Nicoll JMV, Treuren B, Acharya BA, Ahlen K, James M. Retrobulbar anaesthesia: the role of hyaluronidase. Anaesth Analg 1986, 65: 1324-8.

${ }^{6}$ Watts MT and Pearce JL. Day case cataract surgery. Br J Ophthalmol 1988, 72: 897-9.

${ }^{7}$ Bloomberg JB. Administration of periocular anaesthesia. J Cataract Refract Surg 1986, 12, 677-9. 